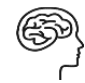

\title{
Habilidades socioemocionales en adolescentes mexicanos
}

Socio-emotional skills in Mexican adolescents

Habilidades socioemocionais em adolescentes mexicanos

\author{
Vanessa Ramírez \\ Universidad Autónoma de Guerrero, México \\ https://orcid.org/0000-0002-6515-3679 \\ Kenny Acuña \\ Universidad Autónoma de Guerrero, México \\ https://orcid.org/0000-0002-3686-7138 \\ Isaac Engler \\ Universidad Autónoma de Guerrero, México \\ https://orcid.org/0000-0001-6757-0364
}

D0I: https://doi.org/10.35622/j.rep.2021.03.003

Recibido 02/12/2020/ Aceptado 20/07/2021

\begin{abstract}
RESUMEN. Las habilidades socioemocionales son un conjunto de competencias facilitadoras de las relaciones sociales y humanas, además generan comportamientos que son la contraparte de cierto tipo de actitudes que ocasionan problemas de carácter social y emocional. Dicho esto, en el presente trabajo se realizó un diagnóstico en los jóvenes de la preparatoria No. 1 de la Universidad Autónoma de Guerrero, México, con la finalidad de conocer si el desarrollando de dichas habilidades guarda relación con los objetivos planteados por la universidad. Esta investigación se realizó en un contexto escolar y tuvo un corte clínico, considerando los criterios de las habilidades socioemocionales propuestas por el Nuevo Modelo Educativo Integral de la Secretaría de Educación Pública. En cuanto a la metodología esta fue exploratoria, transversal y descriptiva. En conclusión, se considera que un $53 \%$ de los jóvenes se encuentran en una tendencia al rango medio y bajo, mientras que solo el $47 \%$ se encontró en la tendencia saludable. Esto confirma que la educación socioemocional no se ha implementado adecuadamente y es necesario una intervención pedagógica integral oportuna.
\end{abstract}

PALABRAS CLAVE: Diagnóstico, estudiantes, habilidades socioemocionales, modelo educativo.

ABSTRACT. Socio-emotional skills are a set of facilitating competencies of social and human relationships; in addition, they generate behaviors that are the counterpart of certain types of attitudes that cause problems of a social and emotional nature. In the present work, a diagnosis was made in the young people of the high school No. 1 of the Autonomous University of Guerrero, Mexico, to know if the development of these skills is related to the objectives set by the university. This research was carried out in a school context and had a clinical cut, considering the criteria of socio-emotional skills proposed by the New Comprehensive Educational Model of the Ministry of Public Education. Regarding the methodology, it was exploratory, transversal, and descriptive. In conclusion, it is considered that $53 \%$ of young people are in a trend in the middle and low range, while only $47 \%$ were in the healthy direction. This confirms that socio-emotional education has not been correctly implemented, and a timely comprehensive pedagogical intervention is necessary. 
KEYWORDS: Diagnosis, students, socio-emotional skills, educational model.

RESUMO. As habilidades socioemocionais são um conjunto de competências facilitadoras das relações sociais e humanas, além de gerar comportamentos que são a contrapartida de certos tipos de atitudes que causam problemas de ordem social e emocional. Dito isso, no presente trabalho foi feito um diagnóstico nos jovens do ensino médio $n^{0} 1$ da Universidade Autônoma de Guerrero, no México, a fim de saber se o desenvolvimento dessas habilidades está relacionado aos objetivos traçados pela universidade. Esta pesquisa foi realizada em contexto escolar e teve recorte clínico, considerando os critérios de habilidades socioemocionais propostos pelo Novo Modelo Educacional Integral do Ministério da Educação Pública. Quanto à metodologia, foi exploratória, transversal e descritiva. Em conclusão, considera-se que 53\% dos jovens estão em tendência na faixa média e baixa, enquanto apenas $47 \%$ estão na tendência saudável. Isso confirma que a educação socioemocional não foi devidamente implementada e uma intervenção pedagógica abrangente e oportuna é necessária.

PALABRAS CLAVE: Diagnóstico, alunos, habilidades socioemocionais, modelo educacional.

\section{INTRODUCCIÓN}

Las habilidades socioemocionales constituyen un conjunto de competencias facilitadoras de las relaciones sociales. La empatía y la capacidad de escucha abren la puerta a comportamientos prosociales, que actúan como contraparte de actitudes discriminantes de todo tipo como el machismo, la xenofobia o el racismo que ocasionan múltiples problemas de carácter social y emocional; además, las competencias sociales permiten generar un clima social favorable al trabajo en grupo ameno y productivo (Bisquerra, 2005). Se entiende que existe una estrecha relación entre los factores sociales y emocionales siendo elementos importantes en el desarrollo de las personas. Para que dicho desarrollo sea pleno y saludable, las habilidades socioemocionales son una pieza clave ya que coadyuvan en la generación de entornos sociales más seguros para los niños y los jóvenes. Estas habilidades permiten la prevención de una gran cantidad de problemas tanto a nivel individual como a nivel interpersonal lo que las convierte en competencias que deben fomentarse en las instituciones educativas.

La educación emocional es una herramienta indispensable en la prevención de problemas como consumo de drogas, contagio de enfermedades de transmisión sexual, violencia física y psicológica, anorexia, intentos de suicidio y autolesiones (Bisquerra, 2005, p. 99). Asimismo, favorece el mejor manejo del estrés y mejora la capacidad de adaptación del sujeto al contexto y en general a las circunstancias de la vida (Mikulic et al., 2015). Es importante mencionar que la falta de trabajo en equipo y la reducción de las interacciones sociales son los problemas más frecuentes entre los adolescentes (Passarotto, 2012 citado 
en Aguilar et. al., 2015). Este tipo de comportamiento contrasta con el de una persona que ha desarrollado sus habilidades socioemocionales, además representa un obstáculo para la producción de entornos sociales seguros en los que prevalece la empatía y la cooperación. Por consecuencia, los jóvenes con pocas habilidades socioemocionales tienden a centrar su atención y tiempo a actividades poco constructivas como la televisión, las redes sociales, etc. En la práctica estas y otras actividades confunden el sentido de la preparación para la vida y hace que los adolescentes se vuelvan apáticos y poco solidarios con las problemáticas de su entorno social.

Es necesario agregar que existe una difusión de mensajes que promueven el individualismo, la mediocridad, el consumismo y el control externo de la conducta. Esto ha afectado principalmente a los más jóvenes, quienes manifiestan desmotivación, insatisfacción y apatía (Messing, 2009 citado en Aguilar et. al., 2015; Martínez 2018). Es más, el adolescente siente inmunidad ante una variedad muy amplia de situaciones, la explicación se encuentra en la seguridad que tienen al creer que, por ejemplo, no habrá ninguna consecuencia si mantienen una relación sexual sin protección. Otra forma de ejemplificar lo dicho es el consumo de sustancias tóxicas que se originan por curiosidad, pues aun conociendo el riesgo de desarrollar una adicción subestiman los efectos negativos de dicha sustancia y sobreestiman su capacidad de control. Como se puede observar, este tipo de comportamientos en los jóvenes deriva en que a muy temprana edad se ven involucrados en la drogadicción, la delincuencia, la violencia, las prácticas sexuales irresponsables, abandono escolar y todo tipo de actividades riesgosas, tanto para ellos como para quienes los rodean.

De esta manera se hace notar que los alumnos sin importar su sexo, edad, o grado escolar, carecen del desarrollo de habilidades socioemocionales y han sido participes directa o indirectamente de las conductas de riesgos social antes mencionadas, que evidentemente afectan a la población en general, no hay un tipo de educación que los prepare para enfrentar a estas y otras situaciones. De acuerdo con Muños et. al. (2017) el desarrollo social de los jóvenes del estado de Guerrero se está dando en un ambiente marginado, de violencia, pobreza y rezago; no todos los jóvenes cuentan con las figuras de autoridad debido a que ambos padres trabajan o emigran y se ven obligados a descuidar la educación 
de sus hijos. Otra característica que se percibe en la población guerrerense es el bajo nivel educativo y el desconocimiento de la psicoeducación; asimismo se puede distinguir la falta de las comunicaciones interpersonales que predisponen la violencia y la pérdida de valores.

Considerando los factores de incidencia que contribuyen a la presencia de las conductas de riesgo se destaca que en el marco educativo común o tradicional no se hace énfasis en la educación socioemocional, si bien ésta se encuentra contenida oficialmente en los programas educativos de México del 2017 no recibe el enfoque correcto y se mantiene como un simple discurso que tiende a ser más un complemento educativo que se desliga de la calidad de vida de las personas, a formación de seres humanos empáticos, resilientes, sanos y con valores (Hartley, 2003 citado en Álvarez, 2020). Cabe mencionar que existe preocupación en los docentes por abordar estos temas, así como otros contenidos de la educación socioemocional, porque no cuentan con una capacitación suficiente y oportuna (Álvarez, 2020). Al respecto Hernández et al., (2018) afirma que la investigación sobre la efectividad de los procesos de enseñanza de las habilidades socioemocionales es inexistente y lo que propone es crear instituciones académicas y grupos de expertos para la realización de estudios rigurosos que mejoren el diseño instruccional y las estrategias de capacitación propuesto en el modelo educativo.

La educación en valores y de los sentimientos no pueden ser el resultado de las buenas intenciones y de la improvisación de los docentes sino que deben sujetarse a una sistematicidad e intencionalidad para la consecución de buenos resultados, esto supone la necesidad de una formación continua de todos los profesionales del área educativa, así como la posibilidad de desarrollar proyectos educativos que integren estas cuestiones para el correcto cumplimiento de sus objetivos (Buxarrais \& Martínez, 2009).

La correcta implementación de la educación socioemocional puede llevar a que los jóvenes sean más responsables socialmente y se pueda asegurar un mejor futuro para sí mismos y para la sociedad. Se trata no solo de un medio para la formación de individuos plenos y socialmente participativos sino de un mecanismo de prevención ante múltiples problemas sociales y de salud. Para López (2017) existen aspectos sociopolíticos y económicos que influyen en la promoción de la salud, por lo que es necesario realizar estrategias que tengan 
cambios significativos en los estilos de vida de las personas, esto fortalecerá las practicas saludables, dificultando las prácticas de riesgo. Los comportamientos saludables tienen una base ecológica, se constituyen a partir de las interacciones con el contexto y mediante el aprendizaje personal. Fernández et al (2009) recalca que la prevención primaria se relaciona con la promoción de la salud, esto implica construir estilos de vida, así como acciones a los planes de educación para la salud, aportando contenidos de diversas áreas de aplicación de la psicología como la psicología social, psicología del trabajo, psicología educativa o psicología.

\section{METODOLOGÍA}

\section{A. Método}

La presente investigación se caracteriza por ser: a) exploratoria, porque pretende conocer qué tipo de actitudes son las que más resaltan y cuáles son las habilidades socioemocionales con las que cuentan los jóvenes; b) transversal, porque analiza cierta información, así como datos en tiempos cortos y determinados, además no interviene en el ambiente. De este modo, se logra un resultado y diagnóstico breve sobre la población estudiada; c) descriptiva, porque el propósito consiste en entender el conocimiento y desarrollo de las habilidades socioemocionales en sus dimensiones y habilidades asociadas. Cabe señalar que la selección de la muestra fue aleatoria simple (López \& Juárez, 2004); la selección de la población se desarrolló en el periodo lectivo agosto 2019-enero 2020 con los alumnos de tercer semestre de la preparatoria $N^{\circ} 1$ turno matutino correspondiente a un total de 497 adolescentes (Unidad académica preparatoria $\left.N^{\circ} 1,2019\right)$. El criterio que se tomó en cuenta para seleccionar el tamaño de la muestra fue la edad de la población (15, 16 y 17 años cumplidos) lo que resultó en una cantidad de 299 estudiantes representando así el $60 \%$ del total de jóvenes. El tamaño de la muestra quedó distribuido de la siguiente manera: 
Tabla 1

Distribución de la muestra

\begin{tabular}{cccc}
\hline Grupo & Matricula & Muestra & $\%$ \\
\hline 301 & 53 & N/P & N/P \\
302 & 56 & Prueba Piloto & 84 \\
303 & 56 & 47 & 80 \\
304 & 54 & 43 & 90 \\
305 & 56 & 50 & 72 \\
306 & 56 & 40 & 65 \\
307 & 56 & 36 & 82 \\
308 & 55 & 45 & $70 \%$ \\
309 & 55 & 38 & 60 \\
\hline Total & 497 & 299 & $60 \%$ \\
\hline
\end{tabular}

Nota: tabla de elaboración propia.

\section{B. Instrumentos de investigación}

Para el diseño y validez de la presente escala se tomó en cuenta las investigaciones de Gaeta \& Galvanovskis, (2009) y González et al., (2018), quienes aplican instrumentos similares a la escala de habilidades socioemocionales. Este instrumento está compuesto por 94 reactivos y una escala de actitud Likert. Esta prueba está dividida en cinco dimensiones y sus habilidades especificas: a) autoconocimiento cuenta con 21 reactivos diseñados para evaluar las habilidades atención, conciencia de las propias emociones, autoestima, aprecio y gratitud así como bienestar; b) autorregulación con 22 reactivos que evalúan las habilidades metacognicion, expresión de las emociones, regulación de las emociones, autogeneración de las emociones, perseverancia e iniciativa personal; c) autonomía cuenta con 15 reactivos diseñados para evaluar las habilidades identificación de necesidades y búsqueda de soluciones, liderazgo y apertura, toma de decisiones y compromiso, así como autoeficiencia; d) empatía con 17 reactivos que evalúan las habilidades bienestar y trato digno hacia sí mismo y hacia las personas, toma de perspectiva en situaciones de desacuerdo y conflicto, reconocimiento de prejuicios asociados a la diferencia, sensibilidad hacia personas y grupos que sufren exclusión o discriminación así como cuidado de otros seres vivos y de la naturaleza; e) colaboración cuenta con 19 reactivos diseñados para 
evaluar las habilidades comunicación asertiva, responsabilidad, inclusión, resolución de conflictos e interdependencia. Es importante recalcar que se hizo un piloteo con estudiantes de tercer semestre del turno matutino cuyas edades oscilan entre 15, 16 y 17 años.

Esta escala define la calificación de cada respuesta con un valor de 0 a 5 puntos para caracterizar en la suma total de las puntuaciones, la dimensión autorregulación (puntajes entre 88-110 saludable, 66-87 media y 65 o menos baja), autonomía (puntajes de 60-75 saludable, 45-59 media y 44 o menos baja), empatía (puntajes 68-85 saludable, 51-57 media y 50 o menos baja), colaboración (puntajes de 76- 95 saludable, 57-75 media y 56 o menos baja), autoconocimiento (puntajes de 84-100 saludable, 63-83 media y 62 o menos baja) y diagnostico general (puntaje 376-470 saludable, 282-375 media y 281 o menos baja). Las calificaciones de la escala se interpretan de la siguiente manera: a mayor puntaje mejor conocimiento y desarrollo de las habilidades socioemocionales.

\section{Técnica de recolección de datos}

Para un mayor sustento científico de esta investigación se usó la escala de habilidades socioemocionales que incluye sus 5 dimensiones y habilidades específicas que promueven el funcionamiento favorable de cada dimensión. Por ser este un trabajo de investigación exploratorio de campo se aplicó el instrumento en un solo tiempo, sin manipular e intervenir en las percepciones de los estudiantes al resolver las preguntas presentadas. Esta técnica fue aplicada por cuestiones prácticas y economía de tiempo.

\section{Análisis de datos}

El instrumento aplicado y los datos obtenidos se concentraron en una base de datos para su análisis. Se trabajó en el programa Excel, fueron separados la escala en dimensiones y habilidades especificas; al termino de esto se realizó una descripción de los resultados, para su interpretación y organización se utilizaron gráficas. Se analizó la información obtenida tomando en cuenta el Nuevo Modelo Educativo Integral considerando las siguientes dimensiones: a) autoconocimiento: atención, conciencia de las propias emociones, autoestima, aprecio y gratitud y bienestar; b) autorregulación: metacognición, expresión de las emociones, regulación de las emociones, autogeneración de las emociones y perseverancia; c) autonomía: iniciativa personal identificación de necesidades y búsqueda de soluciones, liderazgo y apertura, toma de decisiones y compromiso, autoeficacia; d) empatía: bienestar y trato digno hacia sí mismo y hacia las personas, toma de perspectiva 
en situaciones de desacuerdo y conflicto, reconocimiento de prejuicios asociados a la diversidad, Sensibilidad hacia personas y grupos que sufren exclusión o discriminación, cuidado de otros seres vivos y de la naturaleza; e) colaboración: comunicación asertiva, responsabilidad, inclusión, resolución de conflictos, interdependencia (Secretaría de Educación Pública, 2017).

\section{RESULTADOS}

Se presentan los resultados obtenidos por dimensiones y habilidades específicas.

\section{A. Dimensión autoconocimiento}

El autoconocimiento es una de las dimensiones que forman parte de las habilidades socioemocionales, es útil para todas las personas, porque fortalece las habilidades y capacidades, refina la conducta y permite alcanzar metas y objetivos. Aunque es un tema que se trabaja poco en los proyectos educativos, se trata de una piedra angular para el proceso de enseñanza-aprendizaje y para el desarrollo de una identidad integral (Chernicoff \& Rodríguez, 2018). Siguiendo con esta idea, la dimensión está centrada en el conocimiento y valoración personal, quienes están atentos a sus emociones y conductas se reconocen a sí mismos y se valoran. Esto les permite formar su identidad y mejorar su relación con el entorno social lo cual les permite mantener un estado de bienestar. De otro lado, las habilidades específicas que componen esta dimensión son: atención, conciencia de las propias emociones, autoestima, aprecio, gratitud y bienestar.

En el caso de la atención, se trata de un proceso cognitivo que dirige los recursos mentales y sensoperceptuales en algún estímulo particular. Dependiendo del campo de estudio del que se aborde se compondrá, definirá y clasificará de distintas maneras, por ejemplo, la neurociencia que ha logrado identificar cuatro funciones básicas, conocidas como funciones ejecutivas, las cuales incluyen la memoria de trabajo, la capacidad de inhibir respuestas, la flexibilidad cognitiva y la atención sostenida (Secretaría de Educación Pública, 2017). La atención es una habilidad que facilita identificar las emociones, pensamientos y previenen las conductas de riesgo.

Por otro lado, la conciencia de las propias emociones es la habilidad especifica que favorece 
el conocimiento de las motivaciones, pensamientos y emociones que se experimentan. Para ello, es necesario tener la capacidad de ser observador y reflexivo en la manera de experimentar y procesar los estímulos del entorno, además de ser consciente de cómo las decisiones y conductas de los diferentes estados mentales y emocionales actúan sobre la misma persona (Lantieri et al., 2018). Esta habilidad genera el conocimiento y reflexión sobre la emoción específica, así como sus causas y consecuencias positivas o negativas derivadas de la expresión emocional, del mismo modo, permite interactuar de manera sana dentro de la sociedad.

Para la Secretaría de Educación Pública (2017) la habilidad especifica autoestima aborda la identificación y aceptación del potencial, capacidades y limitaciones como ser individual y como miembro de la sociedad. El ser consciente de nuestras limitaciones permite buscar alternativas individuales o sociales que ayuden a subsanarlas, entendiendo que esta habilidad es un medio para la aceptación de las cualidades personales que ayudan a desenvolverse de manera saludable en sociedad. Se puede decir que una persona con la habilidad de autoestima tendrá mayor confianza en sus capacidades, respetará a las demás personas, asimismo tomará las críticas con mayor apertura y objetiva.

El aprecio y gratitud conforman la penúltima habilidad especifica que compone a la dimensión autoconocimiento, esta se origina de la apreciación y reconocimiento de las características propias internas y externas. La gratitud se manifiesta mediante emociones placenteras, demostrándose con acciones encaminadas al cuidado y protección del bienestar (Bartlett et al., 2006). En otras palabras, cuando las personas se sienten apreciadas se muestran agradecidas con los demás volviéndose a su vez una fuente de aprecio para los demás siendo así una habilidad que promueve la reciprocidad en las relaciones sociales, por ejemplo, los jóvenes que pertenecen a un grupo se sienten apreciados, en agradecimiento a este sentimiento buscan comportarse de manera agradable con sus pares.

La habilidad especifica bienestar es la última que conforma la dimensión autoconocimiento, esta se relaciona con el hacer y convivir, así como el ser y estar sin limitarse a un estado de ánimo o sensación. Kahneman et al., (2006) sustenta que los individuos deben poseer vida 
en comunidad, educación integral, sustento vital suficiente y digna, ecologías sustentables y democracias multiculturales. Es importante reconocer la influencia del bienestar y su relación con todas las dimensiones que conforman las habilidades socioemocionales, porque el bienestar es el resultado del desarrollo y practica de todas estas. Se entiende al bienestar como una triada de seguridad social, salud física y salud mental. El primer elemento destaca relacionarse con el entorno social de una manera factible, el segundo con el ser o estar saludable físicamente y el tercero se refiere al reconocimiento y equilibrio emocional. El buen funcionamiento de todas las habilidades especificas fortalecerá el bienestar.

Figura 1

Dimensión autoconocimiento y habilidades especificas.

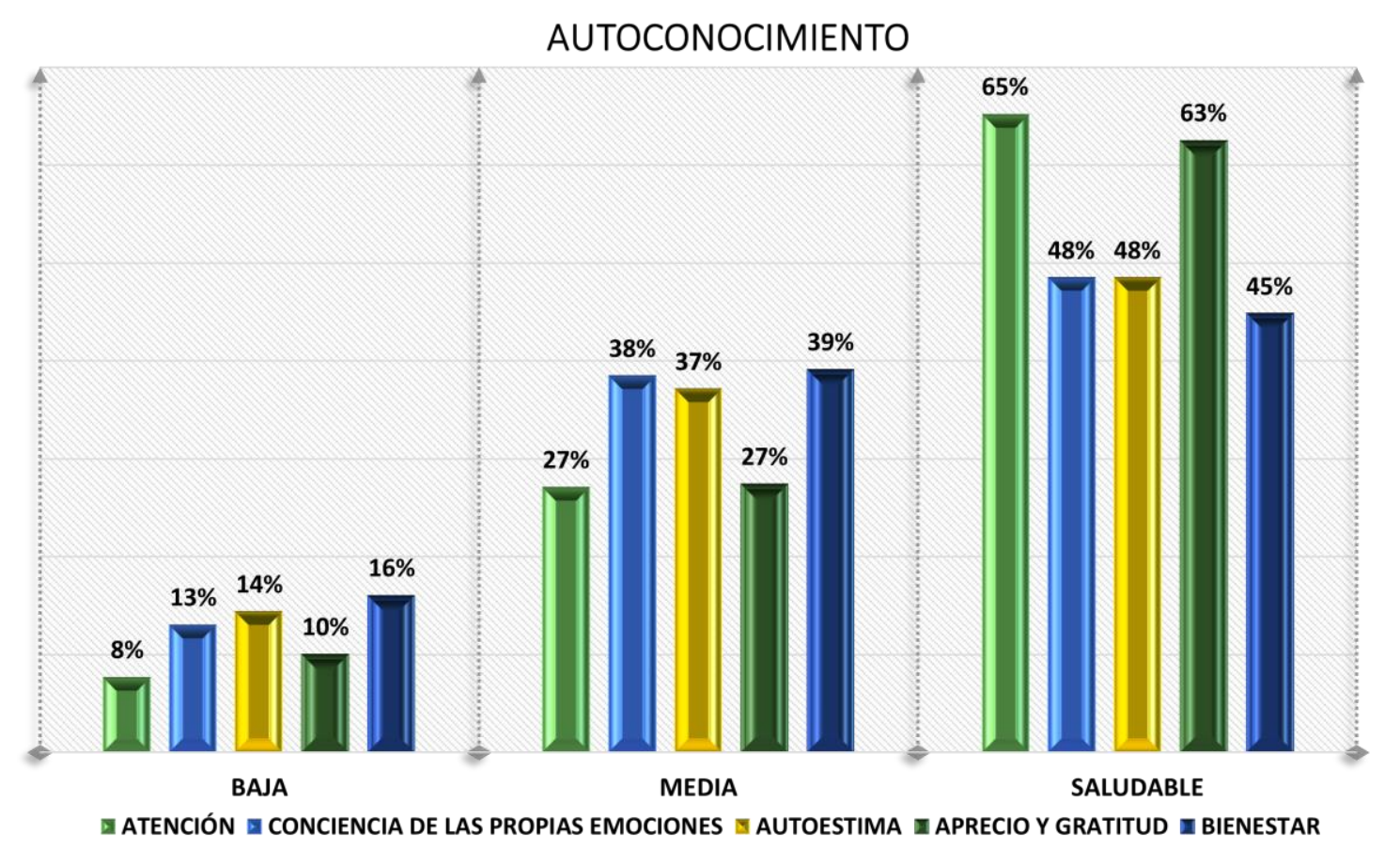

Nota: en la gráfica se muestran los resultados del estudio clasificado en sus tres niveles (baja, media y saludable).

Como se puede observar en la gráfica, la habilidad especifica que requiere mayor cuidado y desarrollo es bienestar debido a que se encuentra por debajo del $50 \%$ teniendo el puntaje más bajo de todas; enseguida resaltan las habilidades especificas conciencia de las propias emociones y autoestima al tener ambas un puntaje que no difiere mucho de la anterior. Cabe mencionar que, aunque estas dos habilidades especificas obtuvieron el mismo puntaje en el rango saludable, la habilidad autoestima tiene mayor representación en el rango bajo lo que la ubica como la segunda habilidad que requiere mayor atención. Continuando con las 
habilidades específicas que sobrepasan el 50\% tenemos las habilidades aprecio y gratitud, así como atención que se perciben con un mayor desarrollo. En general las habilidades específicas en conjunto, se perfilan hacia el rango saludable, sin embargo, se deberá trabajar con todas las habilidades que componen esta dimensión dando mayor prioridad a las habilidades que se alejan más del $100 \%$.

\section{B. Dimensión Autorregulación}

La autorregulación es la dimensión que permite manejar y redirigir pensamientos sentimientos y emociones de manera apropiada, consciente y equilibrada que pueden ser expresadas y comprendidas por sí mismas. La autorregulación conlleva a tolerar la frustración, ser perseverante en el logro de metas pese a las dificultades, así como manejar los impulsos, la duración e intensidad de los estados emocionales, permitiendo experimentar voluntariamente emociones saludables. La represión de las emociones puede ser confundida con la regulación emocional por lo tanto es importante diferenciarlas ya que es fundamental el experimentar emociones de forma consciente para la generación de conductas reflexivas y evitando la impulsividad (Bisquerra, 2009). Cultivar esta dimensión resulta importante, porque hace a las personas más consientes, responsables, reflexivas y pacientes, lo que hace que los jóvenes sean menos propensos a los riesgos sociales al no dejarse llevar por las emociones evitando conductas desadaptativas, por ejemplo, a un joven lo provocan verbalmente para iniciar una pelea, éste por la emoción se verá motivado a responder de manera violenta, sin embargo al tener desarrollada la autorregulación se mantendrá atento a las emociones que lo incitan a actuar de manera agresiva. En consecuencia, toma una decisión más adaptativa, las habilidades específicas que componen esta dimensión son metacognición, expresión de las emociones, regulación de las emociones, autogeneración de las emociones para el bienestar y perseverancia.

La habilidad especifica metacognición, permite regular las emociones y potenciar el aprendizaje al ser consciente de los procesos mentales. Algunos aspectos que favorecen el pensamiento reflexivo son la capacidad de anticipación, de aprender de los errores, la planeación, aplicación de estrategias y diseño de estrategias para la mejora (Secretaría de Educación Pública, 2017). Esta habilidad radica en el reconocimiento, comprensión, reflexión y conciencia de todos los procesos que ocurren en la mente humana, abarcando 
procesos como el pensamiento, las emociones, los impulsos, el aprendizaje, la memoria, la percepción y la atención. Esta habilidad especifica es importante, porque permite conocer el porqué, el cómo y el para qué de todo lo que ocurre en el plano mental brindando capacidades que facilitan anticiparse a los problemas a través de soluciones inmediatas.

La habilidad especifica expresión de las emociones consiste en mostrar de manera clara y respetuosa los sentimientos y emociones considerando el contexto (Bisquerra et al., 2019). Se debe considerar que el estado emocional interno no corresponde necesariamente con la manifestación externa. Es indispensable el reconocimiento del impacto que una expresión emocional tendrá en el comportamiento propio y el de los demás. Esta habilidad promueve la comunicación, demostración y transmisión de los sentimientos, manteniendo una actitud de respeto y empatía lo que genera confianza y permite mantener relaciones interpersonales saludables, entendiendo que las emociones no son por sí mismas negativas si se expresan adecuadamente. La regulación de las emociones es la habilidad que permite manejar la duración e intensidad de los estados emocionales, facilitando el afrontar las situaciones conflictivas y los retos de una manera exitosa y pacifica sin lastimar a otros o así mismo (Bisquerra et al., 2019). Esta habilidad especifica actúa como mediadora de los estados emocionales, ayudando a actuar de manera asertiva y no impulsiva, se diferencia de la habilidad expresión de las emociones, porque actúa directamente en la emoción e indirectamente en la expresión.

La autogeneración de las emociones para el bienestar permite sentir emociones no aflictivas de manera consciente y voluntaria manteniendo la tranquilidad pese a la dificultad de una situación o adversidad. El gestionar emociones como el humor, la alegría y el amor, mejora la calidad de vida y evita decaer ante la adversidad, la resiliencia se basa en esta habilidad (Secretaría de Educación Pública, 2017). Como se puede observar esta habilidad se fundamenta en la evocación intencional y consciente de las emociones consideradas benéficas con la finalidad de mejorar la capacidad de afrontamiento de problemas. La perseverancia se refiere a la entereza que se tiene ante la realización de los objetivos, así como preferir las recompensas a largo plazo, las cuales generan un mayor bienestar, ignorando las recompensas inmediatas que no resultan tan benéficas (Bisquerra et al., 2019). Es más, esta habilidad se centra en la constancia de las personas ante las 
adversidades, el mantenerse perseverante ayudará al logro de los propósitos y dará aliento para continuar con las metas a corto o largo plazo.

\section{Figura 2}

\section{Dimensión autorregulación y habilidades específicas.}

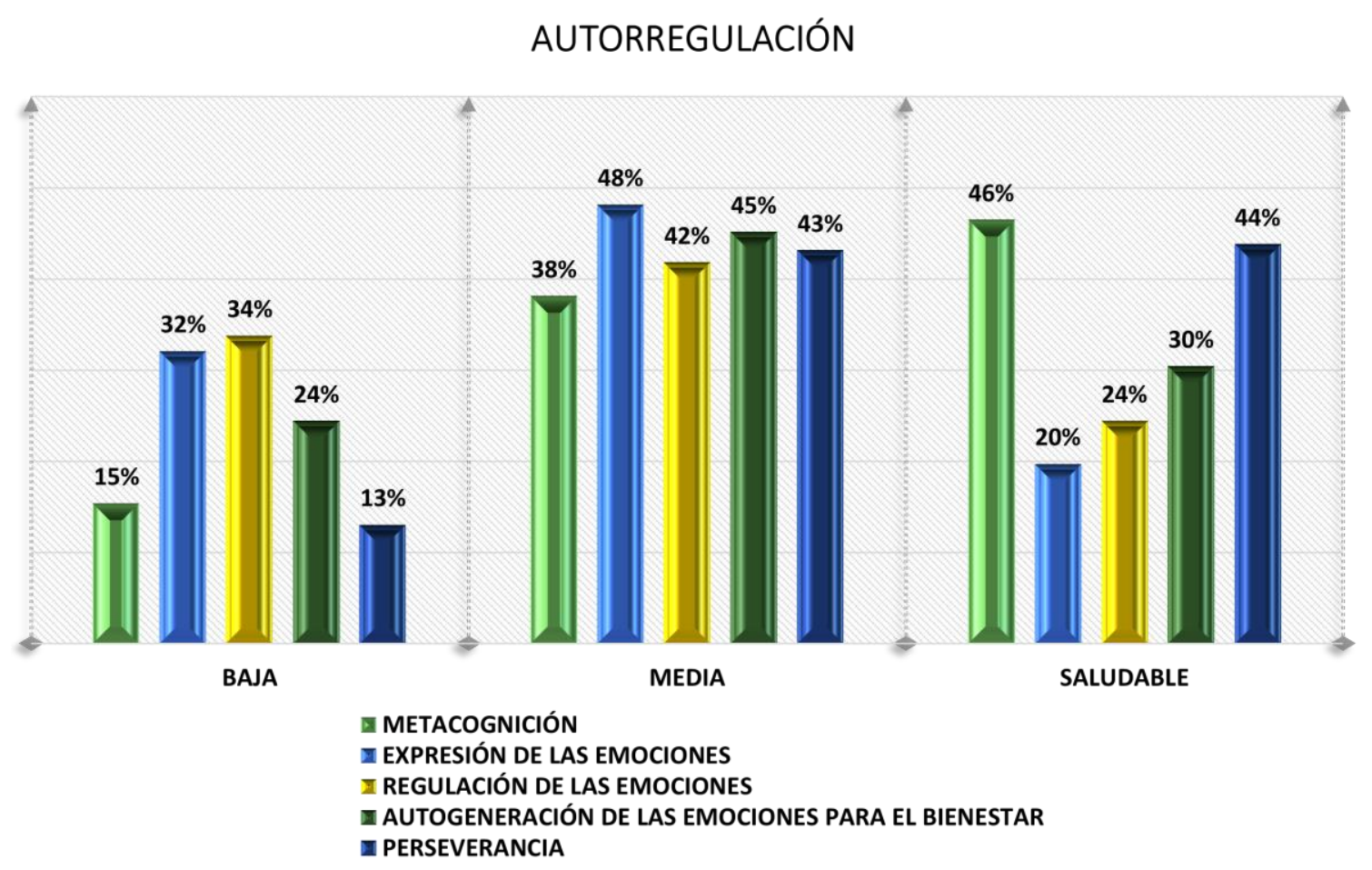

Nota: en la gráfica se muestran los resultados del estudio clasificado en sus tres niveles (baja, media y saludable).

Como se puede apreciar en la gráfica, ninguna de las habilidades específicas obtuvo un puntaje igual o mayor al $50 \%$ en el rango saludable. De estas habilidades la que requiere mayor atención es la habilidad expresión de las emociones, seguida de la regulación de las emociones. La autogeneración de las emociones es la habilidad que se encuentra en tercer lugar, en seguida se encuentran dos habilidades que se acercan al 50\% siendo, nos referimos a la perseverancia la cual se ubica en un $46 \%$ y la habilidad metacognición con un $44 \%$.

Esto las posiciona como las habilidades específicas más desarrolladas de esta dimensión, sin embargo, al mantenerse por debajo del 50\% requerirán un nivel de atención elevado. Cabe resaltar que en su mayoría las habilidades especificas se posicionaron en un conocimiento medio lo cual es un indicativo de que existe cierto grado de desarrollo de las 
habilidades que componen esta dimensión. Lo dicho denota que no se partirá de un estado de desarrollo bajo en su totalidad al momento de abordarlas en un programa de educación socioemocional.

\section{Dimensión autonomía}

La siguiente dimensión es la autonomía, la cual según Kamii (1984) es la capacidad que tienen las personas de decidir y actuar responsablemente con ellas mismas y con los demás. Para el ejercicio de dicha dimensión es necesario confiar en las propias capacidades, es decir, poseer un sentido de autoeficacia, manejando y ejerciendo control sobre las situaciones que nos afectan, así como generar mayores oportunidades de vida de manera individual y colectiva con el desarrollo de actividades. Esta habilidad radica en la independencia personal una vez que se tiene el conocimiento y la regulación emocional, las personas pueden ser autónomas y responsables de sus capacidades al decidir de manera asertiva y madura sobre su vida. Las habilidades específicas que componen esta dimensión son: 1) iniciativa personal, 2) identificación de necesidades y búsqueda de soluciones, 3) liderazgo y apertura, 4) toma de decisiones y 5) compromiso y autoeficacia.

La iniciativa personal depende de un conjunto de conductas y no sólo a una conducta aislada (Lisbona \& Frese, 2012). Estas conductas se caracterizan por tres aspectos: en primer lugar, se trata de conductas autoiniciadas, en las cuales nadie hace una invitación o da una orden para realizar la conducta; en segundo lugar, debe ser proactivo, es decir, ser parte de una anticipación a un problema o situación; el tercero aspecto que debe estar presente es la capacidad de superar las barreras que lleguen a aparecer. De esta forma se trata de una habilidad muy importante, porque ayuda al desarrollo de la libertad, independencia y responsabilidad de los jóvenes, esto tendrá una influencia decisiva en la formación de la propia identidad y del rol que cumplirá en la sociedad.

La identificación de necesidades y búsqueda de soluciones es una habilidad que forma parte de la dimensión autonomía. Esta se hace presente cuando las personas cuestionan su realidad, como resultado genera productos originales en un ámbito específico; por ejemplo, el artístico, el académico el social o el lúdico, combinando sus habilidades y conocimientos requiere la capacidad de buscar soluciones éticas en función del bienestar colectivo, así como tomar perspectiva de las propias necesidades y de los demás (Secretaría de 
Educación Pública, 2017). Esta habilidad se refiere al análisis de las necesidades emocionales, conductuales y sociales, encaminando a las soluciones necesarias para un bienestar personal y colectivo.

La habilidad liderazgo y apertura es la capacidad de vincularse con otros de manera colaborativa para mejorar su entorno, participar activamente en los asuntos que les afectan, practicando el diálogo y la toma de perspectiva, implica cuestionar las propias opiniones y pensamientos manteniendo una actitud reflexiva y de consideración hacia puntos de vista ajenos (Sepúlveda, 2003). Esta habilidad coadyuvara en las relaciones interpersonales debido a que los jóvenes que la practican tendrán más apertura al escuchar las opiniones de las demás personas siendo proactivos y fomentando el dialogo con sus pares. La habilidad toma de decisiones y compromiso que se vincula con la toma de decisiones y la autonomía moral está relacionada con la responsabilidad puesto que brinda la capacidad de actuar de acuerdo a posibles beneficios o perjuicios, sean estos dirigidos hacia uno mismo o hacia los demás (Secretaría de Educación Pública, 2017). Continuando con la idea esta habilidad tiene tres características esenciales que son la libertad individual, la toma de decisiones y la responsabilidad; es decir que las personas deben asumir las consecuencias derivadas de sus decisiones, mismas que son la expresión de su libre albedrio.

La autoeficacia es la habilidad que consiste en la creencia en las habilidades y capacidades personales para organizarlas de tal manera que permitan conseguir los objetivos deseadas. Las personas con una que tienen muy desarrollada esta habilidad tienen una tendencia a realizar tareas desafiantes, así como proponerse metas y objetivos más grandes. Por lo regular, demuestran un mayor esfuerzo, mantienen la perseverancia y un mayor compromiso frente a las dificultades para el logro de metas (Bandura, 1977). Es decir, el desarrollo de la autoeficacia permite valorar los propios alcances y limitaciones, manteniendo la conciencia de estos en la realización de actividades. 


\section{Figura 3}

Dimensión autonomía y habilidades específicas.

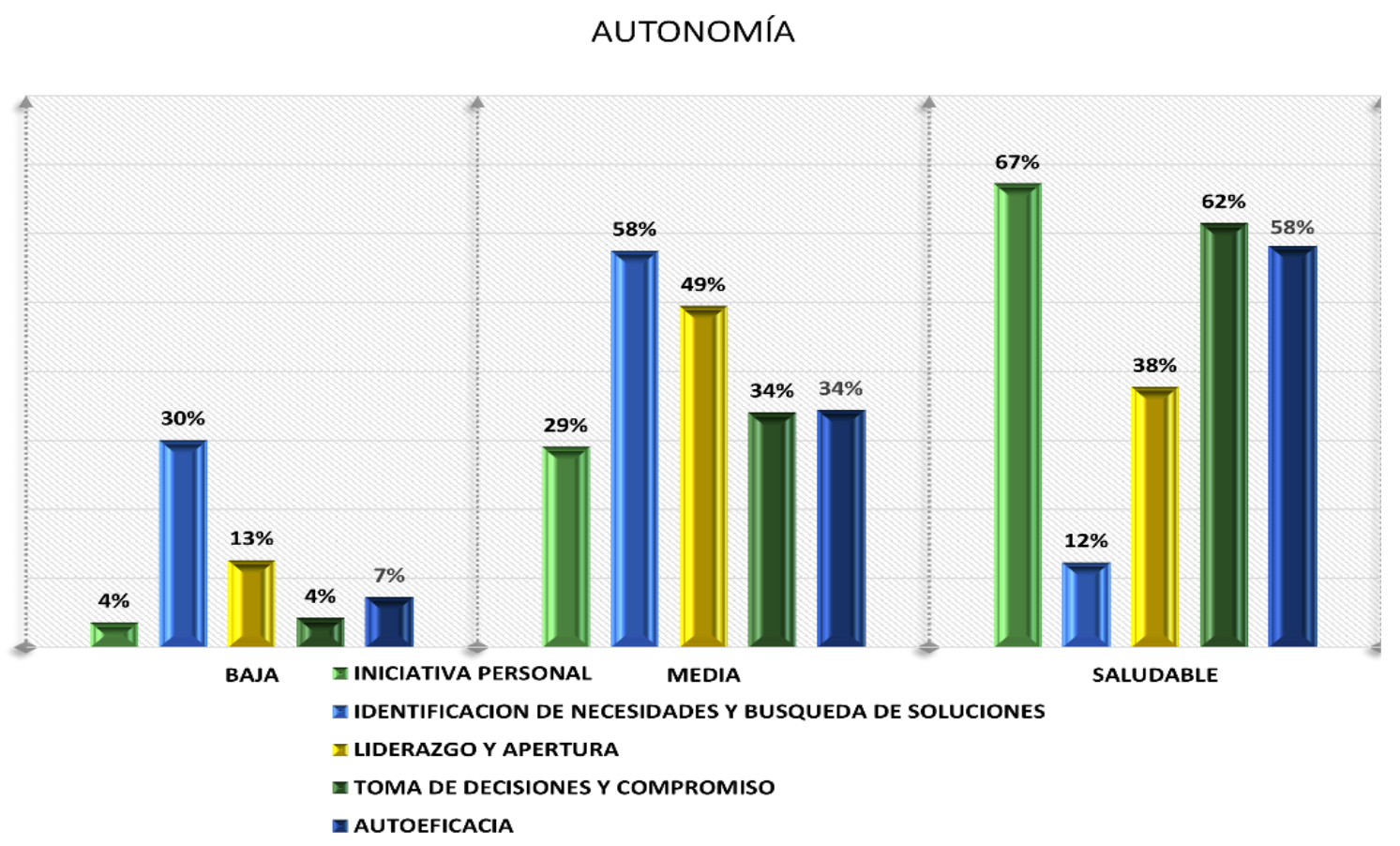

Nota: en la gráfica se muestran los resultados del estudio clasificado en sus tres niveles (baja, media y saludable).

En esta gráfica se observa que las habilidades específicas que se encuentran por debajo del 50\% en el rango saludable son identificación de necesidades y búsqueda de soluciones, así como liderazgo y apertura con un porcentaje de $12 \%$ y $38 \%$ respectivamente. Lo expuesto demuestra que son las habilidades especificas dentro de esta dimensión que requieren una mayor atención. Las siguientes habilidades especificas obtuvieron un porcentaje mayor al $50 \%$ por lo cual se considera que tiene un desarrollo aceptable, ubicándose de la menor a la mayor en el siguiente orden, autoeficacia, toma de decisiones y compromiso e iniciativa personal. Es necesario recordar que, a pesar de encontrarse de un nivel aceptable, son habilidades que conviene desarrollar más, debido a que estas son un complemento que ayudará en la adquisición del resto de habilidades específicas que conforman la dimensión de autonomía.

\section{Dimensión empatía}

La dimensión empatía se puede definir mediante un modelo multidimensional que integra componentes afectivos y cognitivos, los primeros se relacionan con sentir las emociones de 
las otras personas mientras los segundos representan la habilidad de entender los motivos de los estados emocionales de las demás personas; siendo esta la piedra angular para las relaciones interpersonales saludables, así como enriquecedoras, reconociendo y autenticando los sentimientos, las emociones y las necesidades de los demás; fomenta la solidaridad, la compasión y reciprocidad en las relaciones humanas (Secretaría de Educación Pública, 2017). Por lo tanto, la empatía es importante en la formación de las personas debido a que permite un entendimiento mutuo de los sentimientos, pensamientos y acciones mejorando las relaciones humanas fomentando la reciprocidad. Esto quiere decir que una persona empática influye en los demás de manera positiva e incentiva a la práctica saludable de las relaciones humanas, lo que a su vez genera un entorno idóneo para la prevención de los riesgos socioemocionales específicamente la violencia. Las habilidades que conforman esta dimensión son bienestar y trato digno hacia sí mismo y otras personas. El bienestar y trato digno hacia otras personas es una habilidad que pertenece a la dimensión de empatía, se encarga del reconocimiento del valor propio y el de los demás sin importar su condición siendo todos merecedores de respeto cuidado y atención, lo que resultara en sentimientos de bienestar. La capacidad de conectar positivamente con nuestros propios estados emocionales hace posible el reconocimiento de las necesidades y sentimientos de los demás, la autoempatía está relacionada con la simpatía (Aron et. al., 2012).

La habilidad toma de perspectiva en situaciones de desacuerdo y conflicto forma parte de la dimensión empatía y se caracteriza por ser la capacidad de comprender las necesidades, emociones e intereses propios y de otros, así como puntos de vista distintos, aceptándolos y respetándolos, aunque sean contrarios a los propios. Esta habilidad hace referencia a la comprensión de los pensamientos y emociones de las otras personas, mediante una construcción mental de los procesos cognitivos ajenos (Secretaría de Educación Pública, 2017). Esta habilidad se encarga de la reflexión y la manera de reaccionar de las personas cuando las necesidades, emociones e intereses difieren de los propios, así como de la forma en que estas diferencias se afrontan. El desarrollo de esta habilidad es importante porque permitirá prevenir los conflictos en momentos de desacuerdo.

La habilidad sensibilidad hacia personas y grupos que sufren exclusión o discriminación se encarga de la generación de sentimientos de solidaridad, interés y empatía hacia las demás 
personas, principalmente a quienes se les ha quebrantado su integridad como seres humanos. La empatía permite ser recíproco ante los sentimientos de otros siendo una respuesta emocional que se tiene ante las experiencias emocionales ajenas, es decir, la empatía es una respuesta sensible ante la situación de quienes nos rodean por encima de la propia Mehrabian \& Norman (1972). Continuando con la idea, esta habilidad se centra en la generación de pensamientos, emociones y acciones solidarias, anteponiendo las necesidades de las demás personas beneficiando especialmente a los grupos vulnerables.

La habilidad cuidado de otros seres vivos y de la naturaleza, se enfoca en asumir la responsabilidad del cuidado del medio ambiente, así como la conciencia de que los animales y plantas que la conforman sufren. Se trata de un sentido de pertenencia al planeta que habitamos, de igual manera se asume que la empatía puede enfocarse desde una perspectiva situacional y no solamente disposicional (Secretaría de Educación Pública, 2017). De este modo, la empatía demostrada por el sujeto en una situación determinada es mediante acciones concretas, es decir, esta habilidad está centrada en el cuidado de la naturaleza, de la flora y la fauna creando un sentido de pertenencia, de respeto y conexión hacia todos los seres vivos que nos rodean, recordando que compartimos el espacio y los recursos naturales.

\section{Figura 4}

Dimensión empatía y habilidades especificas.

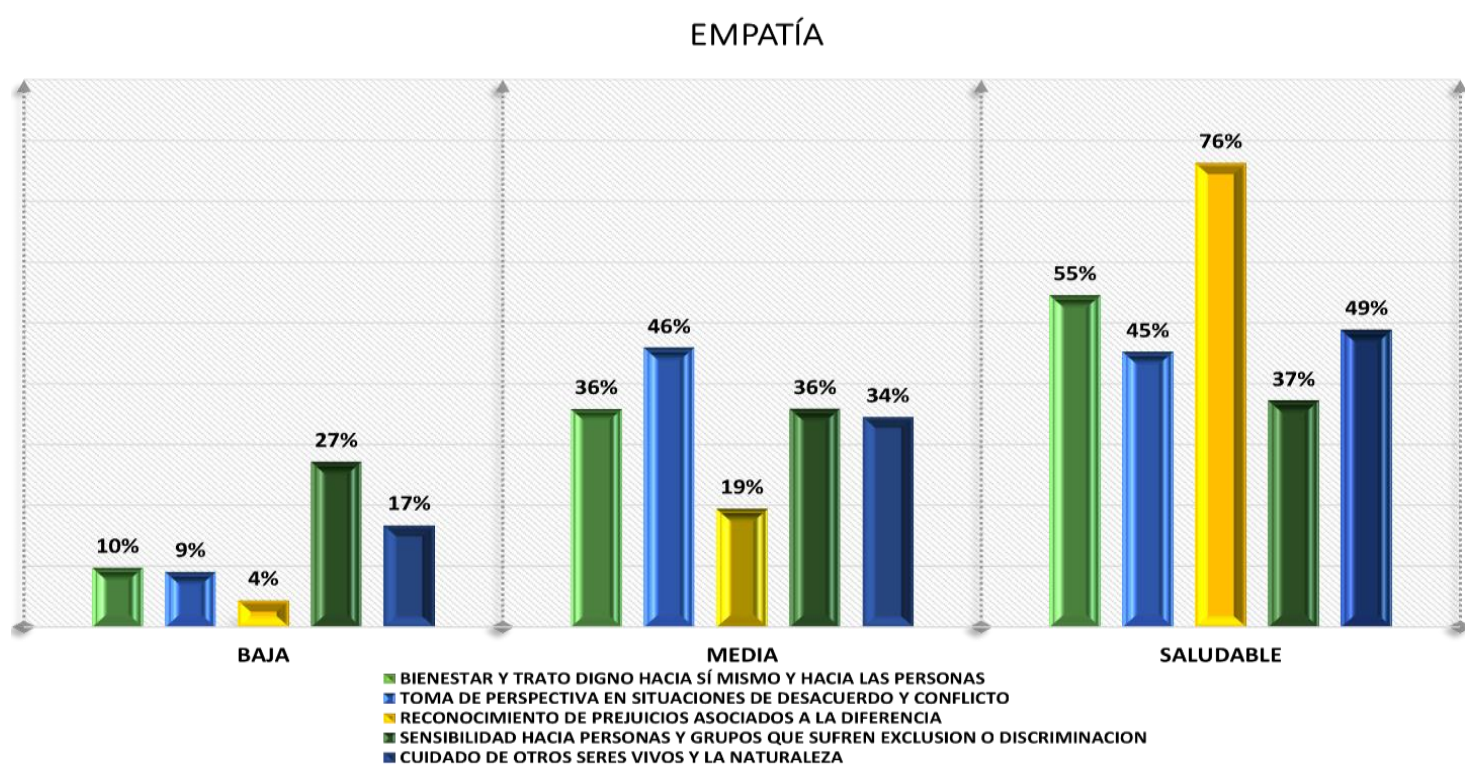

Nota: en la gráfica se muestran los resultados del estudio clasificado en sus tres niveles (baja, media y saludable). 
En esta gráfica las habilidades específicas que se observan por debajo del 50\% son sensibilidad hacia personas y grupos que sufren exclusión o discriminación, toma de perspectiva en situaciones de desacuerdo y conflicto, así como cuidado de otros seres vivos y la naturaleza. Es importante mencionar que estas dos últimas se encuentran muy cercanas al 50\%, por otro lado, las habilidades bienestar y trato digno de sí mismo y hacia las personas, así como el reconocimiento de prejuicios asociados a la diferencia son las habilidades especificas con mayor desarrollo, esto quiere decir que, aunque no obtuvieron un porcentaje totalmente saludable estos se mantienen en un nivel aceptable.

\section{E. Dimensión colaboración.}

La colaboración es una dimensión que forma parte de las habilidades socioemocionales, esta promueve la construcción del sentido del "nosotros", dejando de lado las necesidades individuales y sintiéndose parte de la sociedad, asimismo, aborda la capacidad individual para establecer relaciones interpersonales saludables que lleven a la construcción de metas colectivas (Mungaray et al., 2013). Esta habilidad se desarrolla mediante la práctica del manejo de conflictos, la inclusión, la responsabilidad, la comunicación asertiva y la interdependencia, que interactuando en conjunto ayudan a convivir para hacer y ser en colectividad. Esta dimensión tiene un papel muy importante en el desarrollo de las habilidades socioemocionales, debido a que intercede en las relaciones sociales sanas en las que presta atención a las habilidades individuales para crear un bien comunitario y un sentido de pertenencia colectiva que fomenta la empatía ayudando en la generación de proyectos colectivos.

La comunicación asertiva es una habilidad que forma parte de la dimensión de colaboración, consiste en la capacidad de expresar a través del dialogo pensamientos, sentimientos y emociones de manera pertinente, así como responsable partiendo de una escucha activa, siendo atentos al mismo tiempo que se respetan los puntos de vista individuales. Dicha habilidad permite equilibrar tanto los deseos como necesidades de todos, siendo empáticos, permitiendo la mejora del trabajo en conjunto (Secretaría de Educación Pública, 2017). Se trata de una habilidad que previene conflictos al favorecer el dialogo, ayudando a entenderse de mejor manera y permitiendo la expresión libre, segura, reciproca y sin prejuicios lo que es base para la construcción de una sociedad donde predomine la paz y la armonía creando 
un entorno idóneo para el pleno desarrollo de las capacidades humanas.

La responsabilidad es una actividad voluntaria que se da como consecuencia de la autorregulación y la autonomía, es decir, una persona responsable está dispuesta a hacerse cargo de otra o cumplir con una tarea en específico. Esta habilidad beneficia, garantiza el trabajo en equipo y el aprendizaje colaborativo. Cabe mencionar que el exceso de responsabilidad hacia otros puede impedir que la persona se desarrolle libremente al resultar invasivo (Fromm, 2002). Como se puede observar, esta habilidad es una herramienta indispensable para el desarrollo de una actitud colaborativa al permitir la realización de actividades que requieren un trabajo en conjunto, de esta manera se fomenta el crecimiento, aprendizaje, comunicación, proactividad y solidaridad de todos los miembros de un grupo.

La inclusión es una habilidad especifica que se puede entender como un proceso en el cual se toman medidas que permitan la aceptación de la diversidad creando un sentimiento de pertenencia, arraigadas en el pensamiento del valor intrínseco que existe en cada persona, reconociendo que tiene potencial y debe ser respetada, independientemente de sus capacidades, su identidad u origen (UNESCO, 2020).

La habilidad resolución de conflictos se relaciona con las habilidades de respeto, responsabilidad, comunicación asertiva y solidaridad lo que la hace una herramienta fundamental para su buen funcionamiento, solucionando conflictos con los demás, esto hace que la resolución de conflictos sea de las habilidades más importantes por desarrollar en relación con la capacidad de colaboración (Secretaría de Educación Pública, 2017). Se trata de adoptar una actitud de "ganar-ganar" o de satisfacción y bienestar mutuos, permitiendo encontrar una mejor solución ante las desavenencias generadas por los diferentes puntos de vista o necesidades que tienen las personas. Partiendo de esta idea, se puede decir que esta habilidad facilitará la convivencia de los jóvenes con sus pares al establecer pautas para la reducción de los alcances negativos que pueden surgir durante las interacciones sociales. Esta es una habilidad que mantiene un carácter remedial, complementando a otras habilidades preventivas como la comunicación asertiva y la responsabilidad.

La habilidad interdependencia consiste en ser capaces de decidir sobre la propia vida 
entendiendo que los vínculos presentes en el contexto del sujeto tendrán una influencia sobre dicha capacidad. La interdependencia no es una decisión, sino una forma en que las vidas de todos los individuos son sostenidas, por lo tanto, no hay manera de que el sujeto pueda estar fuera de una red vincular. De este modo, el desafío radica en potenciar las posibilidades de decidir de cada persona en cada momento en lugar de promover la no dependencia de sus vínculos (Carmona, 2020). Continuando con la idea, esta habilidad se dirige al sostenimiento de la autonomía de pensamientos, decisiones y emociones propias, así como el reconocimiento de que es inevitable la participación de otras personas para la realización de ciertas actividades, sean estas recreativas, educativas, culturales, deportivas o de cuidados de la salud.

\section{Figura 5}

Dimensión colaboración y habilidades específicas.

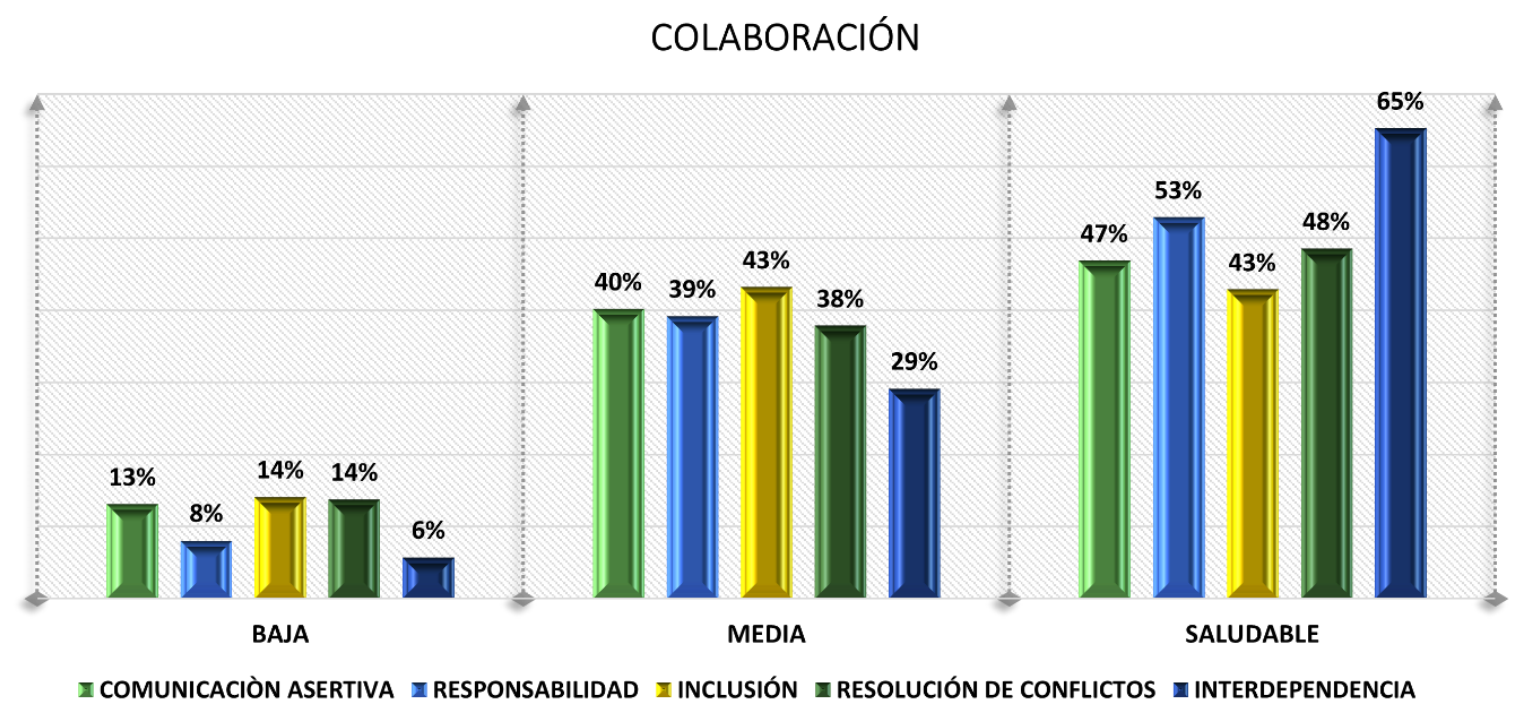

Nota: en la gráfica se muestran los resultados del estudio clasificado en sus tres niveles (baja, media y saludable).

En esta dimensión se puede observar que, la mayoría de las habilidades se encuentran por debajo del $50 \%$ de desarrollo, siendo estas inclusión, comunicación asertiva y resolución de conflictos ubicándose está más cercana al 50\%. La habilidad responsabilidad se encuentra en el $53 \%$ y la interdependencia es la habilidad que tiene un mayor desarrollo, obteniendo el $65 \%$. 
Figura 6

Diagnóstico habilidades socioemocionales.

DIAGNOSTICO GENERAL

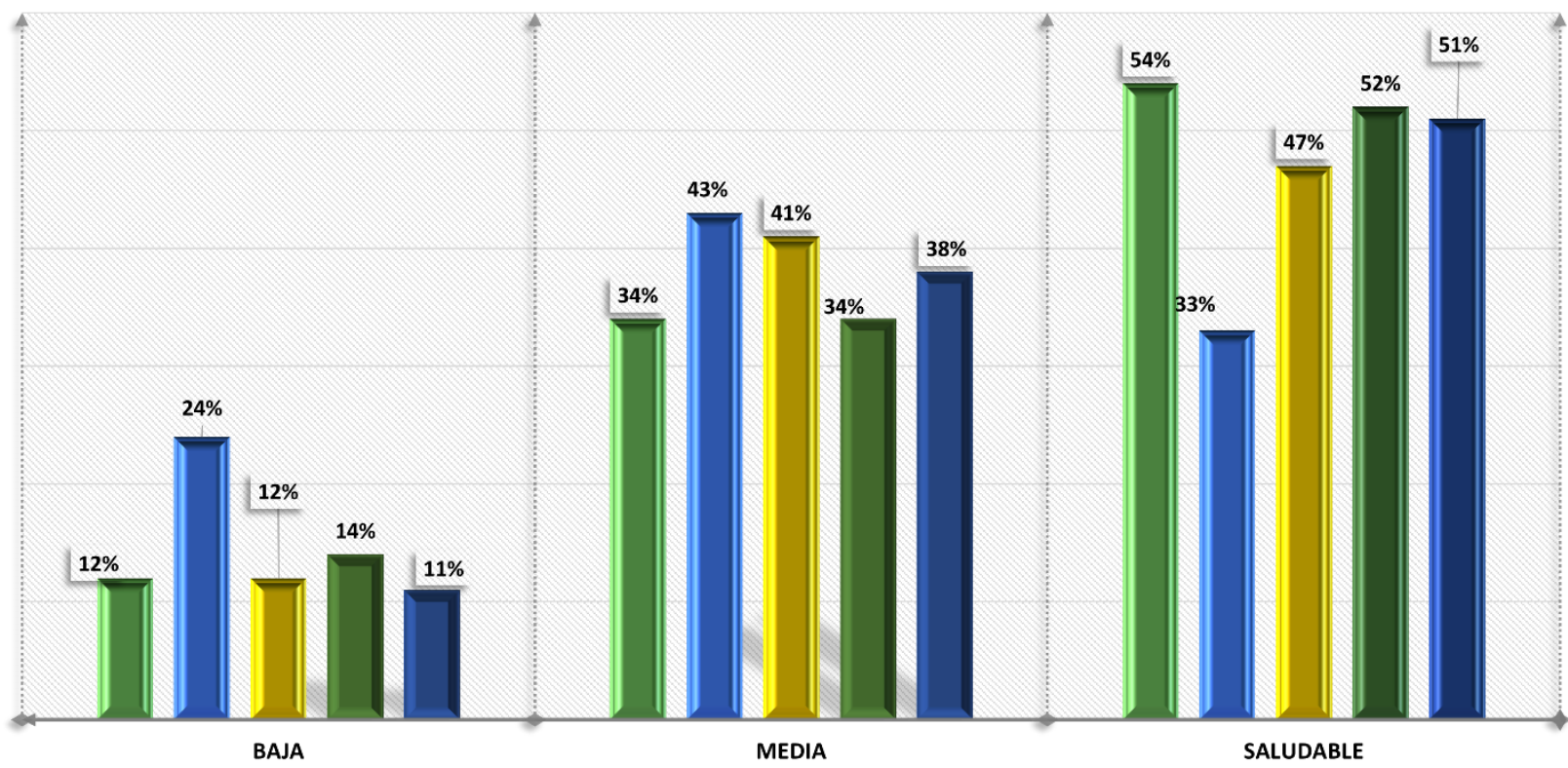

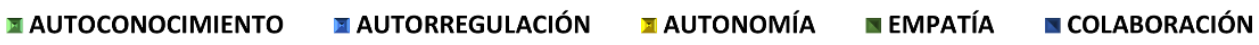

Nota: en la gráfica se muestran los resultados del estudio clasificado en sus tres niveles (baja, media y saludable).

Los datos muestran que la dimensión autorregulación y autonomía se encuentran en un 33\% y 47\% respectivamente y requieren mayor atención; las dimensiones de colaboración, empatía y autoconocimiento se encuentran en un 51\%, 52\% y 54\% en el mismo orden. Si bien es cierto que estas tres últimas dimensiones rebasan el $50 \%$ no quiere decir que tienen un desarrollo saludable, todas ellas requieren de una intervención psicológica para lograr que se encuentren por encima del $80 \%$. Es necesario resaltar que estas dimensiones se complementan unas a otras ayudando o dificultando su desarrollo en conjunto. En el caso específico de la autorregulación, la cual se encuentra con el porcentaje más bajo en el rango saludable, al trabajar en ella se podría potenciar el desarrollo de las demás dimensiones, al mismo tiempo la mejora de dichas dimensiones crearía un entorno socioemocional benéfico para el desarrollo en conjunto de todas las habilidades que conforman las dimensiones. 


\section{DISCUSIÓN}

Las habilidades socioemocionales no están desarrolladas en un nivel aceptable dentro de la población estudiada, cabe mencionar que la dimensión de autorregulación tiene un menor desarrollo, esto da a entender que los jóvenes no son perseverantes, responsables, reflexivos ni pacientes, parece prevalecer en ellos una tendencia a la impulsividad (Bisquerra, 2009). Es decir, los adolescentes son más propensos a desarrollar conductas desadaptativas como peleas, abuso de sustancias o autolesiones, conductas que evidencian la falta de componentes emocionales, porque se encuentran en un nivel muy bajo en los jóvenes, lo que hace que no expresen ni regulen sus emociones, teniendo problemas para lograr un sentimiento de bienestar emocional utilizando la autogeneración de emociones (Bisquerra et al., 2019).

La dimensión de autonomía también se ha encontrado menos desarrolladas en los jóvenes. La habilidad identificación de necesidades y búsqueda de soluciones resalta como la menos desarrollada de todas, esto es un foco de atención debido a que los jóvenes no reconocen sus necesidades emocionales y sociales dando como resultado la práctica de soluciones deficientes, problemáticas y de riesgo (Colom \& Fernández, 2009). Otra de las habilidades que resultó baja en el análisis fue liderazgo y apertura, lo que indica que en los jóvenes existe una tendencia a ignorar las opiniones de los demás manteniéndose pasivos ante los problemas y mostrando desinterés en la participación del dialogo con sus pares, motivo por el cual no ejercen ningún tipo de influencia en su entorno social (Fernández, 2017). Por otro lado, la capacidad de los jóvenes en las habilidades de autoeficacia, iniciativa personal, así como toma de decisiones y compromiso se encontró en un nivel aceptable; se puede observar que estas habilidades están ligadas a la acción más que al análisis e interacción con otros. Esto se debe al bajo nivel que tienen en la identificación de necesidades y búsqueda de soluciones, así como su carencia de liderazgo y apertura, afectando el desempeño global de esta dimensión.

La dimensión que sobrepasa por muy poco en un nivel medio de desarrollo saludable es la colaboración, en esta dimensión las habilidades que no muestran la fortaleza aceptable son: inclusión, comunicación asertiva y resolución de conflictos lo que demuestra que los jóvenes tienden a excluir a sus compañeros en actividades que requieren un trabajo en conjunto, así 
como a mantener actitudes poco reflexivas que no ayudan en las situaciones conflictivas (Hernández, 2008; Ayuntamiento de Vitoria-Gasteizko Udala, 2015). Las habilidades responsabilidad e interdependencia se reflejaron en un rango aceptable, indicando que en algunas situaciones los jóvenes incluyen y fomentan en crecimiento, el aprendizaje la comunicación y la solidaridad; continuando con la idea, los jóvenes no respetan los pensamientos, conocimientos, emociones ni la participación de otras personas en actividades que requieren un trabajo en equipo.

La dimensión de empatía se encuentra en un nivel aceptable, las habilidades que se encuentran menos desarrolladas en esta dimensión son: sensibilidad hacia personas que sufren exclusión o discriminación, toma de perspectiva en situaciones de desacuerdo y conflicto, cuidado de otros seres vivos y la naturaleza. La primera denota el bajo interés por incluir a otras personas que se encuentran en condiciones distintas a las propias en actividades que tengan un beneficio comunitario lo cual genera más segregación social al mismo tiempo que atenta contra la dignidad de las personas discriminadas (Medina et al., 2015); la segunda señala una dificultad para mantener una actitud reflexiva y actuar de acuerdo a las necesidades e intereses ajenos (Martín et al., 2006); la tercera hace referencia al bajo o nulo sentido de pertenencia, así como el descuido de la flora y la fauna lo que significa que existe un desinterés en los jóvenes por el medio ambiente y que traerá consecuencias negativas para todos (Edel \& Ramírez, 2006). En cuanto al bajo desarrollo del bienestar y trato digno hacia sí mismo y hacia las personas podemos referir que los jóvenes no practican la reciprocidad con los demás ni son cuidadosos con sus pensamientos y deseos lo que dificulta las relaciones sociales (Aron et al., 2012). Por otro lado, el bajo desarrollo de reconocimiento de prejuicios asociados a la diferencia señala que los jóvenes no reconocen ni aceptan la diversidad de pensamientos, sentimientos y acciones de otras personas; el bajo desarrollo de empatía genera en los jóvenes una retracción social, baja inclusión y apatía ante las relaciones sociales y con el medio ambiente haciéndolos propensos a ser jóvenes solitarios.

En cuanto a la dimensión autoconocimiento se ubica en un desarrollo medio es decir que, aunque podría tomarse como aceptable no está en un desarrollo deseable. De acuerdo con Fernández (2017), la falta de autoconocimiento en los adolescentes repercute de manera 
decisiva en una baja capacidad de liderazgo. Las habilidades que dentro de esta dimensión se perfilaron al nivel bajo son: conciencia de las propias emociones, autoestima, así como bienestar, resaltando una vez más la dificultad que los jóvenes tienen para reflexionar sobre las causas y consecuencias de sus emociones lo que impide el conocimiento personal (Muñoz \& Morales, 2008). Se puede observar que existe un bajo desarrollo en el bienestar, lo que interfiere en la falta de práctica en el resto de habilidades, afectando el equilibrio emocional, la interacción social, así como la salud física y emocional (Kahneman et al., 2006). Existe una mayor práctica de la habilidad atención, sin embargo, no se encuentra completamente desarrollada, esto puede afectar el desarrollo cognitivo y las conductas prosociales, así como de regulación emocional en los jóvenes (Schonert-Reichl et al., 2015).

\section{CONCLUSIONES}

Las habilidades socioemocionales son un conjunto de competencias que ayudan en la creación de entornos sociales saludables y seguros, siendo importantes para el sano desarrollo emocional e interpersonal en los estudiantes de la preparatoria No. 1 de la Universidad Autónoma de Guerrero. Podemos afirmar que de manera oficial existen programas en las escuelas destinados a educar a los alumnos de manera socioemocional, sin embargo, los resultados que se reflejan en esta investigación muestran la falta de cumplimiento y desarrollo de dichos programas. Dicho esto, podemos decir que en esta investigación se abordó y analizó el desarrollo de las habilidades socioemocionales bajo los estándares del modelo educativo integral de la Secretaría de Educación Pública 2017. Se observó que las habilidades socioemocionales no se encuentran plenamente desarrolladas en la población estudiada, el nivel de conocimiento sobre ésta es de medio a bajo, asimismo, las habilidades que sobrepasan el nivel medio es en un porcentaje mínimo, lo que indica que existe la necesidad de una intervención psicológica en todas las habilidades específicas, permitiendo así el desarrollo de las mismas en su conjunto por la interrelación que existe entre ellas, lo que conlleva al establecimiento de estrategias que impacten en lo teórico, práctico y actitudinal.

\section{REFERENCIAS}

Aguilar Montes de Oca Yessenia Paola, Valdez Medina José Luis, González Arratia, López Fuentes Norma Ivonne, Rivera Aragón Sofía, Carrasco Díaz César, Gómora Bernal 
Alma, Pérez Leal Anel, \& Vidal Mendoza Samantha. (2015). Apatía, desmotivación, desinterés, desgano y falta de participación en adolescentes mexicanos. Enseñanza e Investigación en Psicología, 20(3), 326-336. https://www.redalyc.org/pdf/292/29242800010.pdf

Álvarez Bolaños Esther. (2020). Educación socioemocional. Controversias y Concurrencias Latinoamericanas, 11(20), 388-408. https://www.redalyc.org/journal/5886/588663787023/html/

Aron Ana Maria, Milicic Neva, \& Armijo Iván. (2012). Clima Social Escolar: una escala de evaluación -Escala de Clima Social Escolar. Universitas Psychologica, 11(3), 803813.

Ayuntamiento de Vitoria-Gasteizko Udala. (2015). Resolucion pacifica de conflictos guía de recursos y experiencias prácticas para educadores/as (1st ed., Vol. 1). Asociación matiz educación en valores.

Bandura Albert. (1977). Self-Efficacy: Toward a unifying theory of behavioral change. Psychological Review, 2(84), 191-215. https://doi.org/10.1037/0033-295x.84.2.191

Bandura Albert. (1986). Social Foundations of thought and action: A social cognitive theory. (1st ed., Vol. 1). Prentice-Hall.

Bartlett, Monica, \& David Desteno. (2006). Gratutude and prosocial behavior: Helping when it costs you. Psychological Science, 17(4), 319-325. https://doi.org/10.1111/j.14679280.2006.01705.x

Bisquerra Alzina Rafael. (2005). La educación emocional en la formación del profesorado. Revista Interuniversitaria de Formación Del Profesorado, 13(3), 95-114. https://www.redalyc.org/pdf/274/27411927006.pdf

Bisquerra Alzina Rafael. (2009). Psicopedagogía de las emociones (1st ed., Vol. 1). Síntesis. Bisquerra Alzina Rafael, Bisquerra Prohens Aina, Cabero Jounou Mireia, Fiella Guiu Gemma, García Navarro Esther, López Cassá Elia, Moreno Romero Carolina, \& Oriol Granado Xavier. (2019). Educación emocional propuestas para educadores y familias (4th ed., Vol. 1). Desclée De Brouwer. 
Buxarrais Estrada María Rosa, \& Martínez Martín Miquel. (2009). Educación en valores y educación emocional: propuestas para la acción pedagógica. Teoría de La Educación. Educación y cultura en la sociedad de la información, 10(2), 263-275.

Carmona Gallego, D. (2020). Autonomía e interdependencia. La ética del cuidado en la discapacidad. Revista Humanidades, 10(2). https://doi.org/10.15517/h.v10i2.41154

Chernicoff Minsberg Leandro, \& Rodríguez Morales Emiliana. (2018). Autoconocimiento: una mirada hacia nuestro universo interno. Didac, 72, 29-37. https://biblat.unam.mx/hevila/Didac/2018/no72/6.pdf

Colom Bauzá Joana, \& Fernández Bennassar Maria del Carmen. (2009). Adolescencia y desarrollo emocional en la sociedad actual. International Journal of Developmental and Educational Psychology, 1(1), 235-242.

Edel Navarro Ruben, \& Ramírez Garrido Ma. del Socorro J. (2006). Construyendo el significado del cuidado ambiental: un estudio de caso en educación secundaria. REICE. Revista Iberoamericana Sobre Calidad, Eficacia y Cambio En Educación, 4(1), $52-70$.

Fernández Alves Raida, Carmo Eulalio María do, \& Jiménez Brobeil Sylvia Alejandra. (2009). La promoción de la salud y la prevención de enfermedades como actividades propias de la labor de los psicólogos. Arquivos Brasileiros de Psicología, 61(2), 1-12. https://www.redalyc.org/pdf/2290/229019248009.pdf

Fernández Barba Felipe de Jesús. (2017). El desarrollo del liderazgo en adolescentes en ambientes educativos no formales. Congreso Nacional de Investigación Educativa, 14(1), 1-13.

Fromm Erich. (2002). El arte de amar (2nd ed., Vol. 1). Paidós.

Gaeta González Laura, \& Galvanovskis Kasparane Agris. (2009). Asertividad: un análisis teórico-empírico. Enseñanza e Investigación en Psicología, 14(2), 403-425.

Hernandez Cervantes Vianey. (2008). Desarrollo de la comunicación asertiva, para favorecer el rendimiento escolar de los adolescentes de primer grado de secundaria.

Hernández Zavala Martha, Trejo Tinoco Yuriria, \& Hernández Miriam. (2018). El desarrollo de habilidades socioemocionales de los jóvenes en el contexto educativo. RED, 1(9). 
Kahneman, Daniel, y Krueger, \& Adam. (2006). Developments in the measurement of subjetive well-being. Journal of Economic Perspectives, 20(1), 3-24. https://www.aeaweb.org/articles?id=10.1257/089533006776526030

Kamii Constance. (1984). Autonomy: The Aim of Education Envisioned by Piaget. The Phi Delta Kappan, 65(6), 410-415. https://www.jstor.org/stable/20387059

Lantieri, Linda, \& Daniel Goleman. (2018). Building emotional intelligence: Techniques to cultivate inner strength in children. (1st ed., Vol. 1). Electronic University.

Leyva Muños Oliva, Caribe Ana Maria, \& Luis Espinoza Eduardo. (2017). Guerrero una democracia compleja (Aréstegui Rafael, Ed.; Plaza y Valverdes).

Lisbona Ana, \& Frese Michael. (2012). Iniciativa personal como hacer que las cosas sucedan (1st ed., Vol. 1). Pirámide.

López Jiménez Paco. (2017). Competencias socioemocionales y salud en educación social. Educació Social. Revista d'Intervenció Socioeducativa, 66, 51-69. https://raco.cat/index.php/EducacioSocial/article/view/326401

López Lugo Elsa Karina, \& Juárez García Francisco. (2004). Apuntes de Métodos y Técnicas de Investigación en Psicología Social(1st ed., Vol. 1). Instituto Nacional de Psiquiatría Ramón de la Fuente.

Martín García María Jesús, Gómez Becerra Inmaculada, Chávez Brown Mapy, \& Douglas Greer. (2006). Toma de perspectiva y teoría de la mente: aspectos conceptuales y empíricos. una propuesta complementaria y pragmática. Salud Mental, 29(6).

Martínez Bueno Cristina. (2018). La prevención de comportamientos de riesgo en los jóvenes: estrategias educativas. Matronas Profesión, 2(3), 10-10.

Medina Mejía Virginia, Coronilla Contreras Ukranio, \& Bustos Farías Eduardo. (2015). La discriminación dentro del salón de clases. RIDE Revista Iberoamericana para la Investigación y el Desarrollo Educativo, 6(11).

Mehrabian Albert, \& Norman Epstein. (1972). A measure of Emotional Empathy. Journal of Personality, 4O(4), 525-543. https://doi.org/101111/j.1467-6494.1974.tb00078.x 
Mikulic Isabel Maria, Radusky Pablo David, \& Caballero Romina Yanina. (2015). Evaluación de las competencias socioemocionales en contexto. VII Congreso Internacional de Investigación y Práctica Profesional En Psicología XXII Jornadas de Investigación XI Encuentro de Investigadores en Psicología del MERCOSUR., 1(SN), 39-42.

Mungaray Ana Marcela, González Rosa María, \& Ramírez Miguel Ángel. (2013). Las comunidades emocionales en la escuela. In Xocolocotzi Angel Mateos Jose Antonio (Ed.), Los bordes de la filosofía educación, humanidades y universidad (1st ed., Vol. 1, pp. 97-106). Itaca.

Muñoz de Visco Elina Nora, \& Morales de Barbenza Claribel. (2008). Grupos de autoconocimiento: recurso para favorecer el desarrollo personal. Fundamentos En Humanidades, IX(17), 163-178.

Schonert-Reichl, K. A., Oberle, E., Lawlor, M. S., Abbott, D., Thomson, K., Oberlander, T. F., \& Diamond, A. (2015). Enhancing cognitive and social-emotional development through a simple-to-administer mindfulness-based school program for elementary school children: A randomized controlled trial. Developmental Psychology, 51(1). https://doi.org/10.1037/a0038454

Secretaría de Educación Pública. (2017). Aprendizajes clave para la educación integral (1st ed., Vol.

https://www.planyprogramasdestudio.sep.gob.mx/descargables/aprendizajes_clave _para_la_educacion_integraL.pdf

Sepúlveda Ramírez María Gabriela. (2003). Autonomía moral: Una posibilidad para el desarrollo humano desde la ética de la responsabilidad solidaria. Revista de Psicologia, 12, 27-35. https://www.redalyc.org/articulo.oa?id=26400102

UNESCO. (2020). Resumen del Informe de Seguimiento de la Educación en el Mundo 2020: Inclusión y educación: todos sin excepción. (2nd ed., Vol. 1). Organización de las Naciones Unidas para la Educación, la Ciencia y la Cultura. https://www.gcedclearinghouse.org/sites/default/files/resources/200213spa.pdf

Unidad Académica Preparatoria no.1. (2019). Lista de alumnos por periodo lectivo, grado, grupo y turno. 